\title{
Educação em saúde: repercussões no crescimento e desenvolvimento neuropsicomotor do recém-nascido
}

Health education: repercussions in the neuropsychomotor growth and development of the newborn Educación en salud: repercusiones en el crecimiento y el desarrollo neurológico y psicomotor del recién nacido

\author{
Karla Oliveira Marcacine', Priscila Lopes Orati", Ana Cristina Freitas de Vilhena Abrão"II \\ ' Universidade Federal de São Paulo, Escola Paulista de Enfermagem, \\ Programa de Pós-Graduação em Enfermagem. (Mestranda). São Paulo-SP. Brasil. \\ "Prefeitura Municipal de Castilho, Secretaria de Saúde, Estratégia Saúde da Família. Castilho-SP, Brasil. \\ Universidade Federal de São Paulo, Escola Paulista de Enfermagem, \\ Programa de Pós-Graduação em Enfermagem. (Mestranda). São Paulo-SP. Brasil. \\ "I' Universidade Federal de São Paulo, Escola Paulista de Enfermagem, \\ Programa de Pós-Graduação em Enfermagem. São Paulo-SP, Brasil.
}

Submissão: 24-11-2010 Aprovação: 09-02-2012

\section{RESUMO}

O período pós-parto caracteriza-se por grandes transformações físicas e emocionais, em que puérperas e familiares muitas vezes experimentam sentimentos e emoções ambivalentes e conflitantes, gerando necessidade de orientação e apoio profissional. Assim, buscou-se avaliar as evidências disponíveis na literatura sobre educação em saúde por parte da equipe de enfermagem para puérpera e familiares sobre cuidados com o recém-nascido, que reflita em seu adequado crescimento e desenvolvimento neuropsicomotor. Realizou-se revisão integrativa da literatura que resultou na análise de sete artigos. Ficou evidente a necessidade de incentivo à participação do núcleo familiar na construção do cuidado à criança potencializando o sucesso dos resultados das ações em saúde, uma vez que proporciona a este núcleo autonomia e confiança em seus atos.

Descritores: Desenvolvimento infantil; Comportamento materno; Comportamento paterno; Enfermagem materno-infantil.

\section{ABSTRACT}

The postpartum period is characterized by great physical and emotional changes, when parturients and families experience ambivalent and conflicting feelings and emotions, especially with the arrival of the baby, requiring the need of professional orientation and support. Having it in mind, it was searched the available literature evidence about health education, coming from a nursing team and directed to parturients and families, dealing with the newly born care and regarding its appropriate neuropsychomotor growth and development. It is clear the need of motivating the mother and the family to participate in the development of child care, increasing the success of health action results, once it provides autonomy and trust to this nucleus towards its acts, especially to the maternal role.

Key words: Child development; Maternal behavior; Paternal behavior; Maternal-child nursing.

\section{RESUMEN}

El período posparto se caracteriza por grandes transformaciones físicas y emocionales, donde las madres y miembros de la familia a menudo experimentan sentimientos y emociones ambivalentes y contradictorias, creando la necesidad de orientación profesional y de apoyo. Hemos tratado de evaluar la evidencia disponible en la literatura sobre educación para la salud por el personal de enfermería para la atención post-parto y la familia sobre el bebé que se refleja en su crecimiento y desarrollo psicomotor, lo que resultó en el análisis de siete artículos. Es evidente la necesidad de fomentar la participación de la familia en el cuidado infantil aprovechando el éxito de los resultados de las intervenciones de salud, ya que proporciona la autonomía central y la confianza.

Palabras clave: Desarrollo infantil; Conducta materna; Conducta paterna; Enfermería materno infantil 


\section{INTRODUÇÃO}

O período pós-parto inicia-se logo após a dequitação placentária e seu término é variável, conforme diferentes autores. Caracteriza-se pelo retorno do organismo materno às condições pré-gravídicas, em torno de 6 a 8 semanas após o parto, um ano ou ano e meio, ou ainda, enquanto durar a lactação ${ }^{(1)}$. Estas modificações estão relacionadas especificamente ao sistema reprodutivo e demais sistemas do organismo(2).

Além da ocorrência dos processos físicos, o período pós-parto envolve diversos significados que representam diferentes níveis de importância para cada mulher, família e comunidade. Hoje, há amplo reconhecimento dos aspectos emocionais da gravidez, parto e pós-parto, e estudos trazem a ideia de que "esse período é um tempo de grandes transformações psíquicas, decorrente de importante transição existencial" $^{\prime(3)}$ que desperta muita ansiedade.

Assim, "é de suma importância considerar as modificações na dinâmica familiar e o redimensionamento do espaço privado que o nascimento de uma criança traz consigo, alterando papéis, modificando antigas relações e delineando novas funções"(4). Os cuidados dispensados a esse período de vida devem contemplar então o binômio mãe-filho, que hoje se amplia para toda a família. O cuidado à saúde da puérpera e o cuidado à saúde do recém-nascido (RN) estão interligados, uma vez que um interfere e influencia direta e indiretamente no outro.

Com o nascimento da criança, para a mulher, inicia-se o processo de adaptação psicológica à maternidade, que é intenso e permeado por importantes transformações pessoais; caracterizado pela vivência de aquisições e perdas irreversíveis nos aspectos físicos, psicológicos e sociais de sua vida ${ }^{(2)}$. Ressalta-se que, para a mãe, existe uma sobrecarga física e psíquica, decorrente do cansaço, presença de dor e deficiência de sono aliada a uma criança que demanda tempo e trabalho ${ }^{(5)}$.

Estudos apontam a estreita relação entre o desfecho da crise vivenciada na gestação e o desempenho do papel materno. Os recursos psíquicos e afetivos, somados às soluções adotadas, pela mulher, durante tal crise podem e resultam, na maioria das vezes, em crescimento pessoal(6-7). O sentimento de ser capaz de realizar a maternagem em todas as suas facetas, confere segurança à mulher tornando-a menos vulnerável à depressão pós-parto, tão frequente nesse período ${ }^{(8)}$.

Dessa forma, o apoio à mulher em seu processo de reorganização psíquica quanto às mudanças corporais, à retomada do planejamento familiar e ao vínculo com seu bebê é necessário, estando listado entre os objetivos do acompanhamento mãe-bebê pelo serviço de saúde, entre outros: avaliação da interação da mãe com o recém-nascido, orientação e apoio à família para amamentação e orientação quanto aos cuidados básicos com o recém-nascido(3).

Devem ser ainda objetivos desse acompanhamento, na lógica do contexto familiar e de integralidade, o estímulo para que a puérpera e seus familiares participem ativamente da consulta e a escuta ampliada ${ }^{(4,9-10)}$, aproveitando o momento para a percepção de seus conhecimentos, identificação da prática de cuidados oferecida ao bebê no domicílio(4,9-10) e de lacunas apresentadas por esses familiares, podendo, a partir daí, estruturar os devidos cuidados e orientações, de acordo com cada caso, problemas e dificuldades identificados ${ }^{(11)}$.

Assim, a atitude do profissional, baseada em uma perspectiva integradora, integral, relacional, de valorização do indivíduo e suas subjetividades, contando com habilidades como a autonomia e o empoderamento do sujeito, a escuta e a empatia ${ }^{(3,10-11)}$, permite-lhe uma prática potencializada, que gera estado de confiança maior na mulher e expande os limites de uma assistência à saúde centrada na criança, considerando o papel fundamental da família, comunidade e demais setores da sociedade nos cuidados à criança $\mathrm{a}^{(4,10,12)}$.

A segurança no papel materno está relacionada ao sucesso do cuidado prestado à criança e à intensificação do vínculo mãe-filho. Estes, por sua vez, geram confiança e fortalecem os laços afetivos da criança para com seus cuidadores ${ }^{(13)}$.

Alguns estudos ${ }^{(9-10)}$ relatam preocupações dos pais com o desenvolvimento dos filhos, ao fazerem comparações com outros filhos ou crianças da mesma idade, como dificuldades do aleitamento materno, estados de doença ou alterações, causando a percepção de certo limite por parte dos pais e insuficiência na relação com os filhos em alguns momentos, gerando a necessidade de orientação e apoio.

Nesse sentido, revelam a potencialidade da atuação do enfermeiro como educador em saúde, auxiliando familiares quanto ao que observar e quais as faixas de padrões esperados, que minimizam as preocupações maternas e paternas, gerando maior segurança em relação ao desempenho da maternidade/paternidade.

A valorização da participação da família no cuidado, orientação e incentivo para a segurança dos cuidados prestados vai ao encontro da necessária reformulação nas práticas das ações básicas preconizadas"(12). "É fundamental considerar como tarefa indispensável dos profissionais a transmissão de conhecimentos, ampliando a autonomia e reforçando a condição de sujeitos sociais, capazes de se autocuidar e cobrar das instituições o atendimento às suas necessidades" (12).

"Diálogos são essenciais para a busca da qualidade de vida, do autocuidado e da cidadania". Desse modo, a enfermagem em saúde da criança pode expandir os horizontes em conjunto com as famílias. A fusão de horizontes não é tomada como junção, os horizontes dos profissionais de saúde e aqueles dos sujeitos que estão sendo cuidados não se misturam, mas se ampliam ${ }^{(10)}$.

Nesse contexto de transformação das práticas, destaca-se a profissão de enfermagem, como um grupo profissional que tem relevantes papéis, funções e responsabilidades no cuidado em saúde. "A essência e especificidade da profissão enfermagem é o cuidado com o ser humano, individualmente, na família e na comunidade, para o desenvolvimento de intervenções de promoção da saúde, prevenção de doenças, recuperação e reabilitação da saúde. A enfermagem se responsabiliza, por meio do cuidado, pelo conforto, acolhimento, bem-estar e autonomia dos pacientes no cuidado em si e na coordenação e intersecção com outros setores, para o oferecimento da atenção à saúde" (10). 
Dentro do processo coletivo de trabalho em saúde, o profissional de enfermagem pode desenvolver um instrumental para atuar independente de critérios patológicos, conquistando maior autonomia, que deve ser aproveitada no sentido de ousar, aprimorar a comunicação com a clientela e ir além da técnica ${ }^{(3)}$. Alguns exemplos de atuações nesse sentido podem ser destacados, como ações de trocas de diferentes vivências entre mulheres e delas com profissionais de saúde, sendo consideradas formas efetivas de intercâmbio de conhecimentos e compreensão da vivência, destacando-se os grupos, e o exame físico realizado pela mãe ou responsável, sob supervisão da enfermeira $^{(5)}$. O enfermeiro é o profissional mais ativo quando se trata de aconselhamento e educação em saúde ${ }^{(11)}$, representando um elo entre os demais profissionais e a comunidade ${ }^{(14)}$.

Frente ao exposto, o presente estudo teve como objetivo avaliar as evidências disponíveis na literatura sobre educação em saúde por parte da equipe de enfermagem para puérpera e familiares sobre cuidados com o recém-nascido, que reflita em seu adequado crescimento e desenvolvimento neuropsicomotor (DNPM).

\section{METODOLOGIA}

Este estudo é uma revisão integrativa da literatura ${ }^{(15)}$, que buscou responder à seguinte questão norteadora: "Há evidências na literatura sobre a educação em saúde por parte da equipe de enfermagem para a puérpera e seus familiares relacionada aos cuidados com o RN que reflita em seu adequado crescimento e DNPM?".

Em busca dessa resposta, foram seguidas as seguintes etapas: estabelecimento da hipótese e objetivos da revisão integrativa; estabelecimento de critérios de inclusão e exclusão de artigos (seleção da amostra); seleção dos artigos, definição das informações a serem extraídas dos artigos selecionados; análise dos resultados e discussão.

As buscas foram realizadas no período de fevereiro a março de 2010, nas bases eletrônicas de dados: Biblioteca Virtual em Saúde (BVS), Literatura Latino-Americana e do Caribe em Ciências da Saúde (LILACS), Base de Dados de Enfermagem (BDENF) e Scientific Electronic Library Online (SCIELO), pelo acesso on-line. A escolha por essas bases de dados objetivou minimizar possíveis vieses no processo de elaboração da revisão integrativa. As palavras-chave utilizadas foram: desenvolvimento infantil (Child Development); comportamento materno (Maternal Behavior); comportamento paterno (Paternal Behavior); cuidados de enfermagem (Nursing Care); enfermagem materno-infantil (Maternal-Child Nursing) e enfermagem familiar (Family Nursing).

Foram incluídos artigos que abordavam educação em saúde por parte da equipe de enfermagem para puérpera e familiares sobre cuidados com o $\mathrm{RN}$ que refletissem no adequado crescimento e DNPM do RN, publicados em português, com os resumos disponíveis nas bases de dados selecionadas, no período compreendido entre 2000 a 2010, independente do método de pesquisa utilizado. Como critério de exclusão, foram adotados artigos que não estivessem disponíveis on-line ou em bibliotecas nacionais.

$\mathrm{Na}$ base de dados SCIELO, foram identificados 12 artigos, sendo sete elegíveis para análise. Dos quatro artigos identificados na BVS, dois foram elegíveis para análise, mas já haviam sido identificados na busca realizada na SCIELO. Na base de dados LILACS, três artigos foram identificados, sendo um elegível para análise; no entanto, também já havia sido identificado na base de dados SCIELO. Na BDENF, dois artigos foram identificados, sendo os dois elegíveis para análise, mas já haviam sido identificados na busca realizada na SCIELO, e um dos artigos também foi identificado na busca realizada na BVS. Portanto, a amostra constituiu-se de sete artigos.

Para a apresentação das informações contidas nos artigos incluídos na revisão integrativa, foi desenvolvido um quadro sinóptico com uma síntese.

\section{RESULTADOS E DISCUSSÃO}

Nos dados do Quadro a seguir, se apresenta a síntese dos artigos incluídos na presente revisão integrativa.

Os sete artigos selecionados foram publicados entre 2000 e 2009, sendo a maior parte das publicações, a partir de 2006. Em relação ao tipo de estudo, dois eram revisões integrativas $^{(10,14)}$ e cinco exploratórios descritivos ${ }^{(4,9,11-13)}$.

Conforme os temas retratados, três artigos analisados referiram-se às ações de enfermagem no acompanhamento e

\begin{tabular}{|c|c|c|c|c|}
\hline Título do Artigo & Autores & Objeto de Estudo & Resultados & Recomendações/Conclusões \\
\hline $\begin{array}{l}\text { Cuidados } \\
\text { maternos a } \\
\text { crianças de } \\
\text { baixo peso ao } \\
\text { nascer. }\end{array}$ & $\begin{array}{l}\text { Débora } \\
\text { Falleiros } \\
\text { de Mello; } \\
\text { Semiramis } \\
\text { Melani } \\
\text { Melo Rocha; } \\
\text { Danielle } \\
\text { Cristine } \\
\text { Martins; } \\
\text { Susana } \\
\text { Zanardo } \\
\text { Chiozi. } \\
(2002)^{9}\end{array}$ & $\begin{array}{l}\text { Relatos maternos } \\
\text { sobre o cuidado à } \\
\text { saúde de crianças } \\
\text { de baixo peso ao } \\
\text { nascer no primeiro } \\
\text { e segundo ano de } \\
\text { vida. } \\
\text { Tipo de Estudo: } \\
\text { Estudo descritivo } \\
\text { exploratório. }\end{array}$ & $\begin{array}{l}\text { Dificuldades relatadas pelas } \\
\text { mães no cuidado com o bebê: } \\
\text { amamentação, alimentação e uso } \\
\text { de medicação; preocupações com } \\
\text { intercorrências, reinternações e } \\
\text { desenvolvimento psicomotor. O } \\
\text { sucesso da continuidade do cuidado } \\
\text { materno está ligado ao suporte } \\
\text { formal dos profissionais de saúde } \\
\text { (tanto técnico como emocional) } \\
\text { e informal da família e sociedade } \\
\text { (que pode ser incentivado pelo } \\
\text { profissional de saúde). }\end{array}$ & $\begin{array}{l}\text { Há necessidade de suporte } \\
\text { profissional para avaliar e } \\
\text { acompanhar o processo de } \\
\text { crescimento e desenvolvimento } \\
\text { infantil no cotidiano das } \\
\text { famílias, garantir a continuidade } \\
\text { do cuidado, o apoio aos pais, a } \\
\text { contribuição para a redução da } \\
\text { ansiedade destes e o vínculo. }\end{array}$ \\
\hline
\end{tabular}




\begin{tabular}{|c|c|c|c|c|}
\hline $\begin{array}{l}\text { O lúdico e o } \\
\text { desenvolvimento } \\
\text { infantil: um } \\
\text { enfoque na } \\
\text { música e no } \\
\text { cuidado de } \\
\text { enfermagem. }\end{array}$ & $\begin{array}{l}\text { Ana Paula } \\
\text { Xavier Ravelli; } \\
\text { Maria da } \\
\text { Graça Corso } \\
\text { da Motta. } \\
(2005)^{13}\end{array}$ & $\begin{array}{l}\text { A relação da } \\
\text { ludicidade da } \\
\text { música com o } \\
\text { desenvolvimento } \\
\text { infantil. } \\
\text { Tipo de Estudo: } \\
\text { Estudo Descritivo. }\end{array}$ & $\begin{array}{l}\text { O cuidado de enfermagem } \\
\text { subsidiado pelo lúdico, por meio de } \\
\text { jogos, brincadeiras, cantos e danças, } \\
\text { assegura um cuidado integral e } \\
\text { cuidadoso. A musicalidade está } \\
\text { inserida em nosso meio, sendo a } \\
\text { música, com sua sonoridade que se } \\
\text { apresenta desde a vida intrauterina, } \\
\text { envolvente e instrutiva. Dessa forma, } \\
\text { contribui na intermediação do } \\
\text { estabelecimento do vínculo afetivo e } \\
\text { socialização. }\end{array}$ & $\begin{array}{l}\text { O brincar é necessário ao } \\
\text { crescimento e desenvolvimento } \\
\text { infantil, uma vez que a criança } \\
\text { se constrói como ser ao interagir } \\
\text { com o outro e o mundo. É } \\
\text { importante o reconhecimento } \\
\text { das fases vivenciadas pelas } \\
\text { crianças, para que se possa } \\
\text { estimular adequadamente e } \\
\text { observar seu desenvolvimento } \\
\text { adequado. }\end{array}$ \\
\hline $\begin{array}{l}\text { A prática da } \\
\text { enfermagem na } \\
\text { atenção à saúde } \\
\text { da criança em } \\
\text { unidade básica } \\
\text { de saúde. }\end{array}$ & $\begin{array}{l}\text { Glória } \\
\text { Lúcia Alves } \\
\text { Figueiredo; } \\
\text { Débora } \\
\text { Falleiros de } \\
\text { Mello. } \\
(2003)^{12}\end{array}$ & $\begin{array}{l}\text { Ações de } \\
\text { enfermagem no } \\
\text { acompanhamento } \\
\text { do crescimento e } \\
\text { desenvolvimento } \\
\text { de crianças } \\
\text { menores de } 5 \text { anos } \\
\text { de idade, usuárias } \\
\text { de duas Unidades } \\
\text { Básicas de Saúde. } \\
\text { Tipo de Estudo: } \\
\text { Estudo descritivo } \\
\text { exploratório. }\end{array}$ & $\begin{array}{l}\text { As ações básicas de saúde da } \\
\text { criança estão permeando a } \\
\text { assistência de enfermagem, } \\
\text { embora de forma fragmentada na } \\
\text { comunicação e vínculo com a } \\
\text { clientela. Ações de saúde referentes } \\
\text { a diagnósticos precoces e/ou } \\
\text { aleitamento materno são mais } \\
\text { eficazes quando se realizam nos } \\
\text { primeiros dias de vida, em que se } \\
\text { deve discutir as ansiedades da mãe } \\
\text { quanto à criança de um modo geral: } \\
\text { incentivo ao aleitamento materno, } \\
\text { orientações alimentares, controle da } \\
\text { diarréia e hidratação oral, controle } \\
\text { das doenças respiratórias, vigilância } \\
\text { do crescimento e desenvolvimento, } \\
\text { imunização básica. }\end{array}$ & $\begin{array}{l}\text { O trabalho em saúde coletiva } \\
\text { oferece oportunidade de uma } \\
\text { visão ampliada, o que deve ser } \\
\text { aproveitado pela enfermagem } \\
\text { contra a lógica centrada na } \\
\text { doença, o que proporciona } \\
\text { maior autonomia em relação } \\
\text { ao médico. Ações educativas } \\
\text { efetivas e de sensibilização no } \\
\text { primeiro atendimento da criança } \\
\text { garantem o vínculo da mãe/ } \\
\text { família com a UBS e estimula } \\
\text { o autocuidado, o que vai ao } \\
\text { encontro da necessidade de } \\
\text { reformulação das práticas nas } \\
\text { ações básicas preconizadas. }\end{array}$ \\
\hline $\begin{array}{l}\text { Atenção à Saúde } \\
\text { da Criança: } \\
\text { Perspectiva } \\
\text { da prática de } \\
\text { enfermagem } \\
\text { comunitária. }\end{array}$ & $\begin{array}{l}\text { Akemi Iwata } \\
\text { Monteiro; } \\
\text { Maria das } \\
\text { Graças } \\
\text { Carvalho } \\
\text { Ferriani. } \\
(2000)^{14}\end{array}$ & $\begin{array}{l}\text { A prática de } \\
\text { enfermagem } \\
\text { na assistência } \\
\text { comunitária à } \\
\text { saúde da criança. } \\
\text { Tipo de Estudo: } \\
\text { Revisão Integrativa. }\end{array}$ & $\begin{array}{l}\text { A prática atual de enfermagem } \\
\text { comunitária é realizada na } \\
\text { perspectiva de acompanhar o } \\
\text { crescimento e o desenvolvimento } \\
\text { da criança no seio familiar, num } \\
\text { trabalho multiprofissional de } \\
\text { visita domiciliar e grupos de } \\
\text { mães, nos quais uma enfermeira, } \\
\text { coparticipante, se destaca por sua } \\
\text { formação em saúde preventiva e } \\
\text { promocional. }\end{array}$ & $\begin{array}{l}\text { Realizar monitoramento das } \\
\text { crianças cadastradas. } \\
\text { Aproveitar a consulta do RN } \\
\text { para a consulta puerperal } \\
\text { integrada. Organização de } \\
\text { grupos para incentivo e trocas } \\
\text { de experiências. }\end{array}$ \\
\hline $\begin{array}{l}\text { Utilização de } \\
\text { instrumento } \\
\text { de registro de } \\
\text { dados da saúde } \\
\text { da criança } \\
\text { e família e } \\
\text { a prática do } \\
\text { enfermeiro em } \\
\text { atenção básica à } \\
\text { saúde. }\end{array}$ & $\begin{array}{l}\text { Juliana Coelho } \\
\text { Pina; Débora } \\
\text { Faleiros de } \\
\text { Mello; Simone } \\
\text { Renata } \\
\text { Lunardelo. } \\
(2006)^{4}\end{array}$ & $\begin{array}{l}\text { Um instrumento } \\
\text { de observação, } \\
\text { entrevista e registro } \\
\text { de dados sobre a } \\
\text { criança e a família, } \\
\text { na prática de } \\
\text { enfermagem em } \\
\text { atenção básica à } \\
\text { saúde. } \\
\text { Tipo de Estudo: } \\
\text { Estudo descritivo } \\
\text { exploratório. }\end{array}$ & $\begin{array}{l}\text { Evidência de potencialidades para } \\
\text { a sistematização da assistência de } \\
\text { enfermagem e para a organização } \\
\text { de informações e de melhores } \\
\text { intervenções em saúde. }\end{array}$ & $\begin{array}{l}\text { A partir da ampliação dos } \\
\text { cuidados de enfermagem junto } \\
\text { às famílias, torna-se necessário, } \\
\text { em saúde da criança, estruturar } \\
\text { a avaliação que envolve a } \\
\text { criança, o grupo familiar e o } \\
\text { ambiente, buscando abordar o } \\
\text { desenvolvimento infantil. } \\
\text { Importância da utilização da } \\
\text { Sistematização da Assistência de } \\
\text { Enfermagem (SAE): é preciso que } \\
\text { haja a compreensão de que uma } \\
\text { linguagem padronizada sobre } \\
\text { a prática de enfermagem faz-se } \\
\text { necessária, mas não se configura } \\
\text { como um gesso. }\end{array}$ \\
\hline $\begin{array}{l}\text { O processo } \\
\text { de trabalho } \\
\text { da enfermeira } \\
\text { no cuidado à } \\
\text { criança sadia em } \\
\text { uma instituição } \\
\text { da seguridade } \\
\text { social do } \\
\text { México. }\end{array}$ & $\begin{array}{l}\text { Yolanda Flores } \\
\text { Peña; Maria } \\
\text { Cecília Puntel } \\
\text { de Almeida; } \\
\text { Rafael Luis } \\
\text { Castillo } \\
\text { Duranza. } \\
(2006)^{11}\end{array}$ & $\begin{array}{l}\text { O processo } \\
\text { de trabalho } \\
\text { da enfermeira } \\
\text { orientado ao } \\
\text { cuidado no } \\
\text { Programa da } \\
\text { Vigilância } \\
\text { e Controle } \\
\text { da Nutrição, } \\
\text { Crescimento e } \\
\text { Desenvolvimento } \\
\text { (VNCD) do menor } \\
\text { de } 5 \text { anos na } \\
\text { Seguridade Social } \\
\text { do México. } \\
\text { Tipo de Estudo: } \\
\text { Estudo descritivo } \\
\text { exploratório. }\end{array}$ & $\begin{array}{l}\text { O processo de cuidado identificado } \\
\text { foi o procedimento-centrado } \\
\text { baseado em protocolos de } \\
\text { atenção, com consultas rápidas e } \\
\text { pouco espaço de interação entre } \\
\text { enfermeira e mãe. No entanto, a } \\
\text { enfermeira foi capaz de produzir, } \\
\text { em ocasiões, trabalho com base em } \\
\text { seu autogoverno, o que lhe permitiu } \\
\text { estabelecer um núcleo de cuidado } \\
\text { mãe/filho-centrado. }\end{array}$ & $\begin{array}{l}\text { A enfermeira poderia contribuir } \\
\text { para maior aproximação } \\
\text { entre profissionais de saúde e } \\
\text { usuários, por meio da escuta } \\
\text { e da produção de vínculo, } \\
\text { e também para alcançar a } \\
\text { integralidade da assistência à } \\
\text { saúde do menor. Isso pode ser } \\
\text { possível mediante o trabalho } \\
\text { vivo, com base em seu } \\
\text { autogoverno, que lhe permite } \\
\text { atuar além da configuração } \\
\text { institucional. Recomenda-se } \\
\text { flexibilização das normas e } \\
\text { rotinas e reflexão educacional } \\
\text { com o pessoal de saúde, } \\
\text { com vistas à integralidade da } \\
\text { assistência. }\end{array}$ \\
\hline
\end{tabular}




\begin{tabular}{|c|c|c|c|c|}
\hline $\begin{array}{l}\text { Êxito técnico, } \\
\text { sucesso prático } \\
\text { e sabedoria } \\
\text { prática: bases } \\
\text { conceituais } \\
\text { hermenêuticas } \\
\text { para o cuidado } \\
\text { de enfermagem } \\
\text { à criança. }\end{array}$ & $\begin{array}{l}\text { Débora } \\
\text { Falleiros de } \\
\text { Mello; Regina } \\
\text { Aparecida } \\
\text { Garcia de } \\
\text { Lima. } \\
(2009)^{10}\end{array}$ & $\begin{array}{l}\text { Os conceitos êxito } \\
\text { técnico, sucesso } \\
\text { prático e sabedoria } \\
\text { da prática } \\
\text { para ampliar a } \\
\text { compreensão } \\
\text { do cuidado de } \\
\text { enfermagem à } \\
\text { criança. } \\
\text { Tipo de Estudo: } \\
\text { Revisão Integrativa. }\end{array}$ & $\begin{array}{l}\text { A assistência prestada à criança nos } \\
\text { serviços de saúde pode ter impacto } \\
\text { limitado se não se considerar que } \\
\text { a mãe, a família, os responsáveis } \\
\text { e cuidadores exercem papel } \\
\text { fundamental na recuperação, } \\
\text { manutenção e proteção da saúde } \\
\text { infantil no domicílio. Contexto } \\
\text { no qual devem ser construídos os } \\
\text { espaços de cuidados da criança, } \\
\text { praticando o cuidado em uma } \\
\text { perspectiva integradora. }\end{array}$ & $\begin{array}{l}\text { A promoção da saúde, } \\
\text { prevenção de doenças, } \\
\text { recuperação e reabilitação } \\
\text { da saúde da criança, de } \\
\text { forma indissociável deve } \\
\text { estar em consonância com } \\
\text { realidades contextualizadas } \\
\text { e compartilhadas entre } \\
\text { profissionais e famílias, } \\
\text { buscando acompanhar o } \\
\text { crescimento e desenvolvimento } \\
\text { infantil, produzir narrativas, } \\
\text { identificar experiências, escolhas } \\
\text { e tomadas de decisão para a } \\
\text { ampliação do cuidado. }\end{array}$ \\
\hline
\end{tabular}

Quadro 1 - Apresentação da síntese de artigos incluídos na revisão integrativa, 2010.

desenvolvimento da criança, na perspectiva do cuidado centrado na família( ${ }^{(4,9-10)}$; um, às ações de enfermagem no acompanhamento e desenvolvimento da criança na perspectiva do

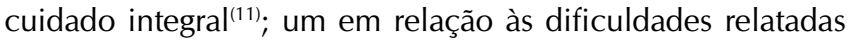
pelas mães nos cuidados com a criança ${ }^{(9)}$; um sobre a relação da musicalidade com o desenvolvimento infantil ${ }^{(13)}$; um da aplicação da Sistematização da Assistência de Enfermagem (SAE) no acompanhamento de crianças na atenção básica à saúde $^{(4)}$; dois em relação às ações educativas, como a organização de grupos ${ }^{(12,14)}$.

Com base na busca realizada por meio da revisão integrativa, foi possível perceber uma escassez de literatura científica em língua portuguesa no que se refere à educação em saúde pela equipe de enfermagem para puérpera e familiares sobre cuidados com o RN, na perspectiva do adequado crescimento e DNPM do RN.

Nenhum dos artigos analisados apresentou-se focado na faixa etária neonatal e período pós-parto, considerando as peculiaridades dos cuidados requeridos pelo $\mathrm{RN}$, bem como pelo DNPM apresentado em cada fase de vida da criança e também pelas condições físicas e emocionais maternas presentes, em níveis diferentes no processo de restabelecimento pós-parto.

Dessa forma, os artigos tratam de ações, orientações, recomendações e práticas destinadas ao cuidado de enfermagem voltado à saúde, crescimento e desenvolvimento infantil, porém de maneira abrangente e, em sua maioria, até o quinto ano de vida.

$U^{(13)}$ aborda a influência de um cuidado específico a ser dado às mães para que se favoreça um adequado crescimento e desenvolvimento infantil, baseado em brincadeiras, especialmente aquelas ligadas à musicalidade e sonoridade. Este estudo aponta a música como parte do contexto do ser humano desde a vida intrauterina, contribuindo na intermediação do estabelecimento do vínculo afetivo e da socialização; e, as brincadeiras, como forma de internalização de vivências e reconhecimento do mundo, como potencialidade para criar e estimular o aprendizado. Assim, é de suma importância que a família seja orientada quanto às fases vividas pela criança, os comportamentos habituais e estímulos necessários, bem como quanto aos tipos de brincadeiras adequadas.

Quatro dos artigos $(9,10,12,14)$ trazem, em linhas gerais, temas importantes a serem abordados no cuidado à saúde das crianças: aleitamento materno; alimentação; orientações quanto ao uso de medicações; imunização; crescimento e desenvolvimento neuropsicomotor; prevenção de acidentes e atenção às doenças prevalentes na infância.

Dos estudos selecionados, somente um deles ${ }^{(9)}$ abordou as dificuldades relatadas pelas mães no cuidado com o bebê: amamentação, alimentação e o uso de medicação; preocupações com intercorrências, reinternações e desenvolvimento psicomotor, valorizando a mãe como coparticipante nas escolhas e decisões sobre sua saúde, de seu filho e sua família, tendo-a como sujeito e não objeto das ações de saúde, possibilitando o processo de educação em saúde e adequado crescimento e desenvolvimento infantil.

Em dois outros estudos ${ }^{(10,12)}$, houve a participação de mães e familiares, porém, abordando a forma como o cuidado à criança é prestado, não considerando, portanto, as temáticas e dificuldades relatadas pelas mães, minimizando a possibilidade de interação profissional-mãe-familiares na produção do cuidado em saúde.

Um dos artigos $^{(4)}$ refere-se à relevância da organização de um instrumento que oriente e facilite a atuação da enfermagem no cuidado à criança e sua família, sugerindo a utilização da SAE, um dos instrumentos básicos do enfermeiro, que tão pouco tem sido utilizado na realidade atual, especialmente na atenção primária à saúde. Esses instrumentos podem e devem ser utilizados à medida que facilitam a atuação do profissional, maximizam os resultados da atenção e possibilitam avaliações sobre a assistência prestada. Dessa forma, esses instrumentos devem ser construídos de forma que sejam flexíveis e possibilitem uma assistência singular a cada indivíduo, de acordo com suas necessidades específicas e contextos de vida.

Três dos estudos ${ }^{(10-12)}$ referem-se aos cuidados materno-infantis, apoiados em uma abordagem familiar e comunitária, integral, humanizada e qualificada. Relatam a transformação das práticas em saúde, a partir de um olhar holístico à saúde, no qual os indivíduos são partes integrantes de um contexto, de um sistema chamado família, para a qual o cuidado é focado que busca a integralidade e promove encontros, vínculos afetivos e a formação de redes de apoio, potencializando as ações de promoção à saúde, prevenção de doenças e a reabilitação de agravos já existentes.

Nesse sentido, as orientações em relação aos cuidados com 
a criança vêm ao encontro da assistência e cuidado integral e de qualidade exercido pela mãe e familiares, uma vez que possibilitam e proporcionam à mãe a vivência do papel materno com mais segurança, trazendo como consequência a autonomia e valorização do ato de cuidar de si e do outro.

Dessa forma, a educação em saúde apresenta-se como uma ferramenta instigadora do cuidado integral e de empoderamento à mulher e sua família, uma vez que, permite uma aproximação do conhecimento cientificamente produzido no campo da saúde com a vida cotidiana das pessoas, oferecendo subsídios para adoção de novos hábitos e condutas em saúde ${ }^{(16)}$, além de permitir um espaço de troca entre o conhecimento popular, advindo das usuárias gestantes e do conhecimento científico dos profissionais de saúde.

Vale destacar que essa relação entre diferentes tipos de conhecimento, deve somar-se, a fim de qualificar a assistência, rompendo com a relação vertical entre usuário e profissional. A promoção da saúde articula saberes técnicos e populares e a mobilização de recursos institucionais e comunitários, públicos e privados. Supera a conceituação biomédica de saúde abrangendo objetivos mais amplos ${ }^{(17)}$.

Todos os artigos analisados possuem como autor o profissional enfermeiro, peça fundamental no processo de ampliar o olhar para as necessidades de saúde do indivíduo, pela busca da integralidade do cuidado, da autonomia e empoderamento dos indivíduos. O enfermeiro é assim, um potencial agente transformador das práticas em saúde, voltadas ao ser humano em suas dimensões biopsicossocioculturais, que priorizam a promoção e prevenção, não deixando de atuar na cura e reabilitação, mas, sim, integrando-as.

\section{CONSIDERAÇÕES FINAIS}

Os achados apresentados por este estudo evidenciam a necessidade de mais estudos em língua portuguesa sobre a temática da orientação quanto aos cuidados e estímulos para com o recém-nascido no período pós-parto, visto que a literatura apresentada é escassa.

A valorização de brincadeiras, musicalidades e sonoridades na atenção e cuidados à criança, introduzindo os mesmos na prática de enfermagem e incentivando-os no cotidiano do cuidado familiar, vem-se demonstrando de grande importância na promoção do vínculo entre mães-filhos, proporcionando maior segurança na experiência da maternidade.

Nesse sentido, o incentivo à participação da mãe e seus familiares na construção do cuidado à criança potencializa o sucesso dos resultados das ações em saúde, uma vez que proporciona a este núcleo autonomia e confiança em seus atos, em especial, o papel materno.

Os resultados salientam que as puérperas devem receber orientações e esclarecimentos em relação aos cuidados com o bebê, sobretudo quanto às temáticas: nutrição; imunização; uso de medicações; crescimento e desenvolvimento; prevenção de acidentes e atenção às condições prevalentes na infância.

A potencialidade da educação em saúde, em especial, quando se tem o enfermeiro como protagonista desta prática é indispensável e necessária para promoção à saúde, assim, é preciso a reflexão das práticas em saúde, ousadia e determinação para investir nesse potencial e utilizar tal energia para a transformação das ações e do indivíduo na lógica da integralidade do cuidado.

\section{REFERÊNCIAS}

1. Mello AR, Neme B. Puerpério: fisiologia e assistência. In: Neme B. Obstetrícia básica. 2a ed. São Paulo: Sarvier; 2000. p. 218-28.

2. Abrão ACFV, Coca K, Pinelli FGS, Abuchaim ESV. Adaptação materna e neonatal. In: Barros, SMO. Enfermagem obstétrica e ginecológica - guia para a prática assistencial. São Paulo: Roca; 2009. p. 221-37.

3. Ministério da Saúde (Brasil), Secretaria de Atenção à Saúde, Departamento de Ações Programáticas Estratégicas. Pré-natal e puerpério: atenção qualificada e humanizada - manual técnico. Brasília (Brasil): Ministério da Saúde; 2005.

4. Pina JC, Mello DF, Lunardelo SR. Utilização de instrumento de registro de dados da saúde da criança e família e a prática do enfermeiro em atenção básica à saúde. Rev Bras Enferm 2006;59(3):270-3.

5. Mattar R, Silva EYK, Camano L, Abrahão AR, Colás OR, Neto JA, Lippi UG, et al. A violência doméstica como indicador de risco no rastreamento da depressão pós-parto. Rev Bras Ginecol Obstet 2007;29(9):470-7.
6. Cury AF. Depressão puerperal. In: Zugaib M, Tedesco JJA. Quayle J. Obstetrícia psicossomática. São Paulo: Atheneu; 1997. p. 206-15.

7. Cury AF, Tedesco JJ. A. Características psicológicas da primigestação. Psicol Estud 2005;10(3):383-9.

8. Bortoletti FF, Silva MSC, Tirado MCBA. Psicodinâmica do ciclo gravídico puerperal. In: Bortoletti FF, Moron AF, Bortoletti J, Nakamura UM, Santana RM, Mattar R. Psicologia na prática obstétrica: abordagem interdisciplinar. São Paulo: Manole; 2007. p. 21-31.

9. Mello DF, Rocha SMM, Martins DC, Chiozi SZ. Cuidados maternos a crianças de baixo peso ao nascer. Rev Esc Enferm USP 2002;36(3):262-9.

10. Mello DF, Lima RAG. Êxito técnico, sucesso prático e sabedoria prática: bases conceituais hermenêuticas para o cuidado de enfermagem à criança. Rev Latinoam Enferm 2009;17(4):580-5.

11. Flores PY, Almeida MCP, Duranza RLC. O processo de trabalho da enfermeira no cuidado à criança sadia em uma instituição da seguridade social do México. Rev 
Latinoam Enferm 2006;14(5):651-7.

12. Figueiredo GLA, Mello DF. A prática da enfermagem na atenção à saúde da criança em unidade básica de saúde. Rev Latinoam Enferm 2003;11(4):544-51.

13. Ravelli APX, Motta MGC. O lúdico e o desenvolvimento infantil: um enfoque na música e no cuidado de enfermagem. Rev Bras Enferm 2005;58(5):611-3.

14. Monteiro Al, Ferriani MGC. Atenção à saúde da criança: perspectiva da prática de enfermagem comunitária. Rev Latinoam Enferm 2000;8(1):99-106.
15. Mendes KDS, Silveira RCCP, Galvão CM. Revisão integrativa: método de pesquisa para a incorporação de evidências na saúde e na enfermagem. Texto \& Contexto Enferm 2008; 17(4):758-64.

16. Alves VS. Um modelo de educação em saúde para o Programa Saúde da Família: pela integralidade da atenção e reorientação do modelo assistencial. Interface - Comunic Saúde Educ 2005;9(16):39-52.

17. Sousa LB, Torres CA, Pinheiro PNC, Pinheiro AKB. Práticas de educação em saúde no Brasil: a atuação da enfermagem. Rev. enferm. UERJ 2010;18(1):55-60. 